\title{
Implementing non-traditional assessment strategies in teacher preparation: Opportunities
} and challenges

Jennifer R. Newton ${ }^{1 *}$, Mira C. Williams ${ }^{2}$, and Danielle M. Feeney ${ }^{1}$

${ }^{1}$ Department of Teacher Education, Ohio University

${ }^{2}$ Department of Educational Foundations and Exceptionalities, James Madison University

*Jennifer R. Newton: newtonj@ohio.edu

Received : 2019-NOV-01

Accepted : 2020-MAY-20

d.

DOI: $10.46303 /$ jcve.03.01.3

How to cite this paper: Newton, J. R., Williams, M. C., \& Feeney, D. M. (2020). Implementing non-traditional assessment strategies in teacher preparation: Opportunities and challenges. Journal of Culture and Values in Education, 3(1), 39-51.

\begin{abstract}
Assessment and grading in higher education have traditionally focused on " $A$ " through " $F$ ", or point-based alpha-numeric letter grades and subjective, independent grading systems. Despite the ubiquity of this system, there are no universal guidelines on how to assess student learning on that scale. What can be problematic about "the way things have always been" is that students are frequently de-humanized; higher education faculty often focus on compliance and authoritarian teaching rather than engaging in the learning process alongside the students. In contrast, some faculty members have explored non-traditional assessment practices in their coursework to enhance the learning process and improve individualized student support. This article offers strategies for implementing non-traditional assessments, specifically mediated office hours, mastery learning, and ungrading strategies are addressed.

Keywords: assessment, ungrading, mastery learning, teacher preparation, collaborative learning
\end{abstract}


Newton, J., Williams, M. C., \& Feeney, D. M., Implementing non-traditional assessment strategies in teacher preparation: Opportunities and challenges

\section{Introduction}

Teaching and assessing the learning of future teachers is a primary responsibility for education faculty; yet faculty may not be learning or implementing the best pedagogical and assessment practices (deBettencourt et al., 2016). There is a dearth of literature about the ways in which faculty in teacher preparation programs are trained to design instruction, teach in face-to-face and online environments, and assess preservice teacher learning. Given the lack of evidence of intentional preparation in meaningfully assessing student learning, most faculty subscribe to the traditional model of grading alone, without collaborating with colleagues for reliability checks on assessments (Brookhart et al., 2016). Disrupting traditional means of assessment provides both opportunities and challenges for faculty.

Colleague and student beliefs and perceptions about assessment are one challenge confounded by the accountability measures, such as the state education departments and higher education accreditation bodies, required of teacher education programs. Quality teacher preparation programs are accredited by a council or board. The purpose of accreditation is to provide standards that ensure students who complete programs know the content, understand students, and engage in clinical experiences that allow them to enter the classroom prepared to teach effectively. The Council for the Accreditation of Education Preparation (CAEP) is an accrediting agency that is approved through state education departments as a body to oversee teacher preparation. CAEP serves as an example here to illustrate how these standards guide and influence teaching, learning, and assessments in teacher education programs. There are five different CAEP standards designed to ensure that "graduates are competent and caring educators" and that faculty "have the capacity to create a culture of evidence and use it to maintain and enhance the quality of the professional programs they offer" (CAEP, 2013). Faculty are tasked with creating "key" assessments aligned to assess each standard and collect data for accreditation. These key assessments are scored on a rubric assigned a value of Exceeds, Meets, or Below Expectations.

\section{Traditional Assessment}

Key assessments are one component of traditional measures of preservice teacher learning. Student work is assessed on an approved, standards-based rubric and recorded as a numerical score for communicating the degree of student mastery of the CAEP standard to which it is aligned. In fact, some key assessments are standardized tests, such as the $\operatorname{Praxis}^{\circledR}$, that are also used as state licensure test requirements. Since these assessments are required and standardized to an extent, there is no flexibility in their traditional implementation or reporting procedures.

Whereas key assessments are fixed, faculty do have the academic freedom to determine the various additional ways learning will be assessed in their courses (Guskey \& Link, 2019). What is measured, how it is measured, and the weight each measure carries is determined by the instructor. Gullickson (1985) divided traditional assessment strategies into the following four types:

- standardized objective tests; 
- teacher-made objective tests;

- essay tests;

- oral quizzes.

It is considered the norm to allot specific percentages to the final grade and compute a grade mathematically to determine the ultimate letter (e.g. " $A$ ", " $B$ "... " $F$ ") to symbolize the students' learning. Additionally, the percentage of points correlated with the letters on the grading scale can also be determined by the instructor (e.g. 90 to 100 points is determined to be an " $A$ "; 94 to 100 points is determined to be an " $A$ "). Therefore, all " $A$ " grades, for example, are not created equally.

\section{Non-traditional Assessment}

While operating within the letter grade system in place across institutions of higher education, some faculty have explored and adopted alternative, non-traditional means of authentically assessing learning. These authentic assessments intend to build the skills in future teachers that they will experience when they are in-service teachers (Villarroel et al., 2017). Self and peer feedback, reflections, revise and resubmit, and narrative feedback lend themselves naturally to a more qualitative approach to making the process of learning visible. The focus in a course where the assignments are "ungraded", a non-traditional model of assessment, shifts from assigning a grade to engaging in ongoing conversation and reflection about the learning. Jesse Stommel, a leader in this work wrote, "Ungrading is not as simple as just removing grades. The word 'ungrading' (an active present participle) suggests that we need to do intentional, critical work to dismantle traditional and standardized approaches to assessment" (Stommel, 2020, para. 10). This critical work helps to humanize the learning process as ungrading creates spaces for conversation and honest reflection. Research suggests that grades do not track learning (Schinske \& Tanner, 2014), but that feedback increases student learning.

Teacher educators must navigate numerous departmental, university, local, state, and national standards, practices, and norms that guide the profession. Navigating this landscape with a non-traditional approach to assessment can be met with opportunities and challenges from both students and colleagues in and outside of the university setting. In this article, the authors discuss these opportunities and challenges as they examine strategies for eschewing traditional assessment practices to implement a non-traditional approach intended to humanize and deepen the learning experiences for both faculty and students. Specifically, traditional approaches to office hours, feedback, and grading will be disrupted by presenting strategies for mediated office hours, mastery learning, and "ungrading."

\section{Disrupting Traditional Office Hours}

Research has shown that increased student-faculty involvement is a critical component of student engagement (Kuh, 2003). This happens in many different ways in teaching and learning contexts; a specific way is in the traditional implementation of office hours. Faculty office hours serve as a chance for students to come in, pose a question or concern, have the question or concern addressed, and leave. When asked about traditional office hours, Smith et al. (2017) found that students stated, "office hours are kind of weird" 
(p. 17). Students indicated two distinct frustrations about the traditional use of office hours: (1) there is a lack of knowledge about their purpose, and (2) traditional office hours may have some potential, but they are not sure what it is. In contrast to students who were uncertain about office hours, a few students indicated that they did identify a purpose for office hours as a chance to pose a question they are unable to ask through email or find independently (Smith et al., 2017). During this time, faculty spend individual time with the student and then expect the student to push forward with the learning process on their own. This is done during a set faculty schedule, often discouraging or even prohibiting students from coming at any other time. When inquiring about student recommendations for creating more advantageous mediated office hour experiences, students suggested that professors differ from the norm by being available and approachable (Smith et al., 2017).

\section{What Do Mediated Office Hours Look Like?}

Mediated office hours change the structure of office hours to offer open collaboration with a focus on shared workspace encourages students to think more critically about the content through continued discourse and collaboration. This practice of mediated office hours allows for faculty and students to interact in intentional, collaborative ways outside of the classroom setting. Fostering student-faculty relationships that go beyond the classroom walls allows for instructors to better understand the future teachers they are preparing for a career in education (Cress, 2008). By maintaining frequent communication, learning about individual needs, and engaging in the learning process together, barriers inherent in hierarchical relationships are diminished (Hoffman, 2014).

Office hours provided as a mediated learning time is rooted in the learning theories of Vygotsky and Feuerstein (Kozulin \& Presseisen, 1995). Students present a topic or assignment that they would like to be more masterful at and the faculty and student work collaboratively towards the student's goal. During the mediated office hours, the instructor and student engage in discourse about the topic, work on the assignment or research together, reach a deeper understanding of the content, and create a shared vision for moving forward. When preparing future teachers, this method not only models the importance of providing individualized support but also illustrates the value of studentfaculty relationships on the learning process (Hoffman, 2014). This mediated learning time also provides additional, intentional support to students who are more vulnerable and benefit from more supported instruction (Quick, 2013).

\section{Student Experiences}

Decades of research indicate that frequent student-faculty contact outside of class is a critical factor in student motivation and involvement, enhancing student intellectual and social development and supporting student persistence and resilience (Chickering \& Gamson, 1987; Cress, 2008; Hoffman, 2014; Tinto, 1997). Initiating interaction outside of the classroom can take many forms: emailing, texting, or calling, and is maintained through frequently shared work sessions in a common space. Although this is traditionally in the faculty member's office, it can occur in more neutral spaces, such as study rooms on campus or nearby coffee shops. Interacting with students in these ways creates student-faculty 


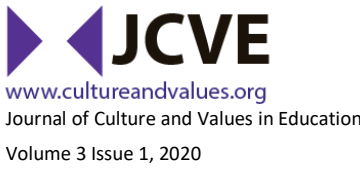

Newton, J., Williams, M. C., \& Feeney, D. M., Implementing non-traditional assessment strategies in teacher preparation: Opportunities and challenges

interactions that support students as individuals. As the faculty member and student better know each other, mediated office hours become increasingly more intentional, collaborative, and goal-oriented. This gives students a greater sense of belonging and increased academic achievement, empowering, and including students more than traditional methods allow for.

Increased student interaction outside of the classroom requires faculty to make themselves available for students. As students request support, increase self-advocacy, and find benefits in mediated office hours, they may maintain more frequent communication. Reliably responding to student needs in order to facilitate relationships and learning experiences requires the faculty member to answer emails, texts, and calls with a sense of urgency, hold open office hours instead of mandating strict time constraints, and encourage students to visit without a specific question in mind. This presents challenges for faculty in balancing the multitudinous demands on their time (Hoffman, 2014).

\section{Colleague Experiences}

In some cases, faculty who see the benefits of the mediated learning sessions, immediate communication, and collaboration between students and instructors attempt to implement similar strategies with their own students. As faculty see the improved outcomes first-hand, more want to learn about incorporating these mediated office hour practices into their daily work. For others, however, the challenges, particularly in time and accessibility, outweigh the benefits.

Traditional office hours are offered so students are able to get targeted support when they are unable to make progress on their own. When colleagues see the amount of support that is provided to a student or the amount of time spent engaged in collaborative learning outside of the classroom, it may be perceived as infantilizing the students or being too "easy." Questions are often posed: "How much support is too much?" or, "Why don't you tell them to go look at the syllabus?" While those are questions worthy of investigating, the work of teaching is collaborative and iterative and dynamic. Mediated office hours provide opportunities to build the culture of learning within a community for students and allows for more intentional dialogue about student progress towards mastery.

\section{Disrupting Traditional Feedback}

Traditionally, students submit work for an instructor to grade. The feedback returned to the student is often a letter grade or a number/percentage correct out of the total possible points. The student may then look to find what they missed or they may not. This approach is ubiquitous, however, concerns about the reliability, validity, and usefulness of this practice are as well (Allen, 2005). Bloom (1971) observed that traditional methods of teaching practice involved organizing instruction by units or standards and then assessing students' knowledge at the end. These culminating assessments did not allow for meaningful feedback loops during the learning experience.

Simultaneously, providing targeted, specific, actionable, and intentional feedback to students preparing to be teachers who will persist in the field has been a top priority. Research suggests that, in Kindergarten-12th grade school settings, teacher feedback has a 


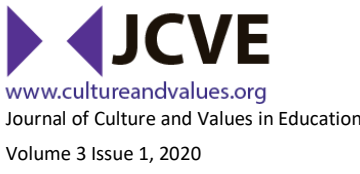

Newton, J., Williams, M. C., \& Feeney, D. M., Implementing non-traditional assessment strategies in teacher preparation: Opportunities and challenges

direct impact on student mindsets (Hattie \& Temperley, 2007) and can encourage a child to persevere through a challenge and increase achievement. While this research examined the teacher's role in primary and secondary education environments, it also pertains to teacher preparation programs. Modeling these feedback skills in teacher preparation and throughout the learning process is vital to the success of preservice teachers and their future students. Mastery learning is one strategy that allows for this continued discourse and feedback loops.

\section{What Does Mastery Learning Look Like?}

From the work of Bloom $(1971,1976,1984)$, mastery learning is rooted in the idea that with time, appropriate learning conditions, and individualized instruction all students will reach a high level of achievement (Guskey, 2010). Bloom (1971) also notes that when checks for understanding occurred throughout learning, the teacher had intentional opportunities to provide feedback on students' individual learning needs and provided further information or activities to help them master content and increase achievement.

Mastery learning approaches are defined by the organization of time and resources to ensure that most students are able to master instructional objectives. A criterion level of performance is established to represent "mastery" of a given skill or concept, rather than the traditional model of providing content and then testing the degree to which students master it. Frequent assessment (or, "formative assessment") of student progress toward the mastery criterion, such as those defined by the professional preparation standards, incorporates iterative feedback and ongoing revisions (Block \& Anderson, 1975; Bloom, 1976). Helping students understand their own learning enhances their achievement and also establishes a foundation on which life-long learning can build (Struyven et al., 2005). This method can look different depending on the course, the content, and even the readiness of the student but in terms of the assessment, mastery learning means that there is no "oneshot, do or die" experience (Guskey, 2010, p. 55).

\section{Student Experiences}

Faculty can implement formative assessments that provide students with on-going and prescriptive feedback when completing an assignment. Assessments are not restricted to a one time due date with a grade determined by faculty at the end, but instead, students are encouraged to: (a) turn in the assignment; (b) receive feedback; (c) engage in reflection and processing (i.e. re-reading content, conferencing, revising) of this feedback; (d) revise the assignment; (e) turn in the assignment again without a loss of points. This is not a "one and done" process, but can instead include multiple iterations. This affords students additional learning experiences and improved levels of achievement. In addition, mastery learning often opens doors for faculty-student conversations (e.g., mediated office hours) and feedback loops that do not occur when a letter grade is assigned with no room for questions, revisions, or improvement. These conversations are vital to a student's learning experience and lead to a deeper understanding of course content.

Mastery learning requires extra time and a commitment to engage in reflection and sometimes difficult conversations. These processes take additional energy and focus even as 


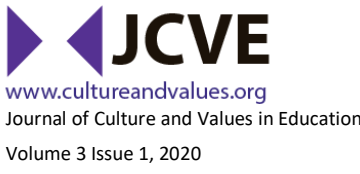

Newton, J., Williams, M. C., \& Feeney, D. M., Implementing non-traditional assessment strategies in teacher preparation: Opportunities and challenges

the course content moves forward. Students may not be familiar and comfortable with receiving feedback and applying it to improve their work (Gustafson \& Thompson, 2013). Therefore, since the process of revise and resubmit can be more time consuming and cumbersome for faculty, it is imperative to thoughtfully and intentionally develop meaningful assessments. Mastery learning challenges students to conceptualize learning beyond the grade, which can be difficult in systems that ultimately require faculty to assign a letter grade at the end of the semester.

\section{Colleague Experiences}

Mastery learning enables colleagues preparing future teachers to model best practices in teaching, as this method is one that allows for individualized learning experiences. Rather than teaching to the course objectives in a "one size fits all" format, mastery learning affords colleagues opportunities to get to know each individual student. These shared learning experiences help colleagues build relationships that extend beyond the course (Tinto, 1997). Finally, engaging in mastery learning practices enables colleagues to help students gain confidence in their own abilities as learners (Anderson, 1994; Kulik et al., 1990; Guskey, 2010).

It can be difficult to engage students in mastery learning as colleagues may feel that it undermines these traditional learning formats. Critics of mastery learning challenge the time required to give meaningful, individual feedback and express concern it makes courses less rigorous and students less responsible (Newbold et al., 2017). Confusion often occurs with grading in mastery learning as one key attribute is to focus on the learning process and student growth instead of letter grades. As we are bound to a system that requires the assignment of a final letter grade (i.e., " $A$ " through " $F$ "), many colleagues believe mastery learning allows every student to get an "easy $A$ ". This misconception perpetuates from a lack of clarity that mastery is determined by the student in conversation with the faculty. Mastery may not result in an " $A$ " for every student, but it will be the student's best work in the context the learning took place. This approach measures the individual student's growth in relation to their personal goals and contexts. Pushing back on the notion that an " $A$ " is the only outcome in mastery learning is yet another disruptive assessment practice.

\section{Disrupting Traditional Grading}

We learn to grade work from our experiences as learners. The only consistent facet of grading in higher education in the United States is the assigning of a letter (i.e., " $A$ " through " $F$ ") to symbolize a composite measure of student performance (Brookhart et al., 2016). Grading scales are perplexing since the work of teaching is not as easily reduced to a numeric value as the traditional norms seem to propose. In traditional models, faculty members are required to provide a course syllabus that outlines course assignments, sets grading expectations, and explains practices that will be used to measure mastery of course objectives, including any key assessments aligned to the course. Due dates are set by faculty before the semester begins and learning is offered through class lectures, outside reading, and assigned work such as exams, papers, and projects. Grades are then assigned and are 


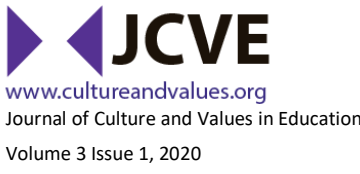

Newton, J., Williams, M. C., \& Feeney, D. M., Implementing non-traditional assessment strategies in teacher preparation: Opportunities and challenges

most often based on attendance, class participation, adhering to the assignment rubrics, and turning in all assignments in compliance with the predetermined due dates.

The purpose of final grades should be to communicate the degree to which content is mastered and, as such, the only items included in the final grade should be artifacts reflecting learning (Allen, 2005). In other words, including participation, attendance, and compliance with policies, as is typical in traditional course assessment, diminishes what the final letter grade communicates. The non-traditional assessment strategies presented thus far focus on student learning and growth, rather than on evaluating or grading.

\section{What Does Ungrading Look Like?}

Eliminating letter grades on student work, assessments, and evidence of learning is a movement referred to as ungrading (Tannock, 2017). There are various ways to assess learning in an ungraded model; however, at the end of the semester, a letter grade is required. This is one of the biggest challenges faced by teacher educators who engage in ungrading as a disruptive practice. Current discussions among scholars who are attempting to remedy this concern have resulted in the following strategies for determining the final letter grade within an ungrading model:

- the goal approach;

- the conferencing approach;

- the reflection approach; or,

- a combination of the three (Flaherty, 2019).

Goal approach. In this approach to ungrading, students set goals for themselves, aligned with the learning objectives of the course, to determine what " $A$ " level mastery of content will look like to them. When the student and instructor come to consensus on the goals and the correlating evidence, the student knows what they need to do in order to get the grade they want on the official University transcript. Students may also determine a "B" or " $\mathrm{C}$ " will be their goal and align their evidence to that end as well. Utilizing mastery learning supports the students to determine their goal and the corresponding letter grade.

Conferencing approach. Here, students and instructors meet throughout the semester, ideally twice at a minimum, to qualitatively assess the student's understanding of course content as aligned with course objectives. Through written products and discussion, students and instructors come to a consensus about how the student's learning can best be represented by a letter grade. They can also set flexible due dates, establish procedures for revisions and resubmissions, and plan to utilize mediated office hours.

Reflection approach. Using this strategy, students write their learning reflection or meet with the instructor to share their learning at the end of a semester. This is an openended strategy for students to reflect on their own role in their learning, the strategies and opportunities that supported their learning, and what could have helped push them further in their experience. Faculty may provide prompts for students to reflect on since this kind of metacognition may feel new and unfamiliar.

The specific approaches, or combinations of approaches, all have two things in common: 1) de-emphasizing faculty assessment of learning with a letter grade and 2) emphasizing students' role in their learning and in evaluating their learning. Research shows 


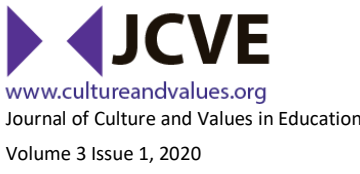

Newton, J., Williams, M. C., \& Feeney, D. M., Implementing non-traditional assessment strategies in teacher preparation: Opportunities and challenges

that grades diminish creativity, risk-taking, and motivation (Brilleslyper et al., 2012). Implementing ungrading strategies shifts the focus from letter grades to feedback focused on improvement (Giles et al., 2010).

\section{Student Experiences}

As educators of future teachers, it is critical to teach the limitations of traditional assessment and the value of authentic assessment (Chen \& Bonner, 2017). When doing so, faculty afford students the opportunity to take control of their learning, which enhances student-faculty relationships and life-long learning (Finsterwald et al., 2013). Even when students are initially hesitant, faculty are able to shift their focus to constant learning, questioning, growing, and experimenting. This eventually builds trust in the process and supports students as they create a more intentional relationship with learning.

Students may not feel trusting of faculty who implement an ungraded approach, apprehensive of the "gotcha" at the end of the course. The "gotcha" happens when students are surprised or unaware of their final grade in a course until the grades are posted at the completion of the semester. Faculty must be consistently reliable and trustworthy, responsive, and available to guide student learning in this way. Students may need support in thinking about their own learning and identifying personal learning goals. Given the limitations of the semester time frame, getting to know each student, their learning profile, and their strengths and needs is a substantial time commitment on faculty.

\section{Colleague Experiences}

Conversations with colleagues about the strategies discussed here can be thoughtprovoking and result in pedagogical discourse that perhaps was not happening before. Typically, colleagues have not questioned their grading scale, what is included in the graded assessments, or how student behaviors are reflected in grading. These conversations could lead to creating program expectations for nebulous and ubiquitous terms in education like "responsible" or "professional," providing students more consistent expectations throughout their preparation program. Faculty have opportunities to align some of their policies and procedures, as well, to make the "hidden curriculum" (i.e. the unwritten, unstated expectations) more transparent for students (Jackson, 1968).

Traditionally assessed courses and courses implementing the strategies here look different from the syllabi all the way to the final assignment of a letter grade. In an ungraded course, the focus is on individualized support which faculty who hold more traditional assessment values may feel is unsustainable or coddling. Anecdotally, colleagues report that ungrading challenges what they have long known to be true about how to effectively prepare and support future teachers. Therefore, it can be challenging for colleagues to consider the benefits for students and faculty in implementing non-traditional approaches.

\section{Conclusion}

"One hundred years of grading research have generally confirmed large variation among teachers in the validity and reliability of grades, both in the meaning of grades and in 
the accuracy of reporting" (Brookhart et al., 2016, p. 35). What can be problematic about "the way things have always been" is that students are frequently de-humanized; higher education faculty often focus on compliance and authoritarian teaching rather than engaging in the learning process alongside the students. While disrupting typical assessment practices can present many challenges, most notably the challenge of time, the strategies presented here have built-in member checks with the students who are engaged in the learning.

Introducing and implementing non-traditional approaches to the assessment of learning in teacher preparation clearly presents both opportunities and challenges. For instructional and untenured faculty, specifically, the urge to blend into program and department norms can be powerful and the consequences for disrupting those norms swift and severe. When faculty feel challenged or threatened by these ideas, finding value in each other's perspectives and experiences becomes limited. This response then results in a broad disconnect for students across coursework, as they navigate widely variable expectations and assessment practices. When faculty feel challenged or threatened by these ideas, finding value in each other's perspectives and experiences becomes limited. This response then results in a broad disconnect for student learning across coursework, as they navigate widely variable expectations and assessment practices. And is student learning not the goal? 
Newton, J., Williams, M. C., \& Feeney, D. M., Implementing non-traditional assessment strategies in teacher preparation: Opportunities and challenges

\section{References}

Allen, J. D. (2005). Grades as valid measures of academic achievement of classroom earning. The Clearing House: A Journal of Educational Strategies, Issues and Ideas, 78(5), 218223. https://doi.org/10.3200/TCHS.78.5.218-223

Anderson, S. A. (1994). Synthesis of research on mastery learning. (ERIC Document Reproduction Service No. ED 382 567).

Brilleslyper, M., Ghrist, M., Holcomb, T., Schaubroeck, B., Warner, B., \& Williams, S. (2012). What's the point? The benefits of grading without points. Primus: Problems, Resources, and Issues in Mathematics Undergraduate Studies, 22(5), 411-427. https://doi.org/10.1080/10511970.2011.571346

Block, J. H., \& Anderson, L. W. (1975). Mastery learning in classroom instruction. Macmillan.

Bloom, B. S. (1971). Mastery learning. In J. H. Block (Ed.), Mastery learning: Theory and practice (pp. 47-63). Holt, Rinehart and Winston.

Bloom, B. S. (1976). Human characteristics and school learning. McGraw-Hill.

Bloom, B. S. (1984). The search for methods of group instruction as effective as one-to-one tutoring. Educational Leadership, 41(8), 4-17. https://www.jstor.org/stable/1175554

Brookhart, S. M., Guskey, T. R., Bowers, A. J., McMillan, J. H., Smith, J. K., Smith, L. F., Stevens, M. T., \& Welsh, M. E. (2016). A century of grading research: Meaning and value in the most common educational measure. Review of Educational Research, 86(4), 803-848. https://doi.org/10.3102/0034654316672069

Chen, P. P., \& Bonner, S. M. (2017). Teachers' beliefs about grading practices and a constructivist approach to teaching. Educational Assessment, 22(1), 18-34. https://doi.org/10.1080/10627197.2016.1271703

Chickering, A. W., \& Gamson, Z. F. (1987). Seven principles for good practice in undergraduate education. AAHE Bulletin, 3-7. https://eric.ed.gov/?id=ED282491

Council for Accreditation of Educator Preparation. (2013). CAEP Standards for accreditation of educator preparation. https://caepnet.org/standards/introduction

Cress, C. M. (2008). Creating inclusive learning communities: the role of student-faculty relationships in mitigating negative campus climate. Learning Inquiry, 2(2), 95-111. https://doi.org/10.1007/s11519-008-0028-2

deBettencourt, L. U., Hoover, J. J., Rude, H. A., \& Taylor, S. S. (2016). Preparing special education higher education faculty: The influences of contemporary education issues and policy recommendations. Teacher Education and Special Education, 39(2), 121133. https://doi.org/10.1177/0888406416641007

Finsterwald, M., Wagner, P., Schober, B., Lüftenegger, M., \& Spiel, C. (2013). Fostering lifelong learning - Evaluation of a teacher education program for professional teachers. Teaching and Teacher Education, 29, 144-155. https://doi.org/10.1016/i.tate.2012.08.009

Flaherty, C. (2019, April 2). When grading less is more. Inside higher ed. https://www.insidehighered.com/news/2019/04/02/professors-reflections-theirexperiences-ungrading-spark-renewed-interest-student 
Newton, J., Williams, M. C., \& Feeney, D. M., Implementing non-traditional assessment strategies in teacher preparation: Opportunities and challenges

Giles, A., Martin, S. C., Bryce, D., \& Hendry, G. D. (2004). Students as partners in evaluation: Student and teacher perspectives. Assessment \& Evaluation in Higher Education, 29(6), 681-685. https://doi.org/10.1080/0260293042000227227

Gullickson, A. R. (1985). Journal of Educational Research, 79(2), 96. www.jstor.org/stable/27540176

Guskey, T. R. (2010). Lessons of Mastery Learning. Educational Leadership, 68(2), 52-57. http://www.ascd.org/publications/educationalleadership/oct10/vol68/num02/Lessons-of-Mastery-Learning.aspx

Guskey, T. R., \& Link, L. J. (2019). Exploring the factors teachers consider in determining students' grades. Assessment in Education: Principles, Policy \& Practice, 26(3), 303320. https://doi.org/10.1080/0969594X.2018.1555515

Gustafson, T. \& Thompson, J. (2013, Nov 11). Demystifying the links between feedback and revision: Ideas for teachers of writing enriched courses. Techniques in learning and teaching. https://uminntilt.com/2013/11/11/demystifying-the-links-betweenfeedback-and-revision-ideas-for-teachers-of-writing-enriched-courses/

Hattie, J., \& Temperley, H. (2007). The power of feedback. Review of Educational Research, 77(1), 81-112. https://doi.org/10.3102/003465430298487

Hoffman, E. M. (2014). Faculty and student relationships: Context matters. College Teaching, 62(1), 13-19. https://doi.org/10.1080/87567555.2013.817379

Jackson, P. W. (1968). Life in the Classroom. Wiley.

Kuh, G. D. (2003). What we're learning about student engagement from NSSE: Benchmarks for effective educational practices. Change: The Magazine of Higher Learning, 35(2), 24-32. www.jstor.org/stable/40177261

Kulik, C.-L. C., Kulik, J. A., \& Bangert-Drowns, R. L. (1990). Effectiveness of mastery learning programs: A meta-analysis. Review of Educational Research, 60(2), 265-299. https://doi.org/10.3102/00346543060002265

Newbold, C., Seifert, C., Doherty, B., Scheffler, A., \& Ray, A. (2017). Ensuring faculty success in online competency-based education programs. The Journal of Competency-Based Education, 2(3). https://doi.org/10.1002/cbe2.1052

Kozulin, A. \& Presseisen, B. Z. (1995). Mediated learning experience and psychological tools: Vygotsky's and Feurstein's perspectives in a study of student learning. Educational Psychologist, 30(2), 67-75. https://doi.org/10.1207/s15326985ep3002 3

Schinske, J., Tanner, K. (2014). Teaching more by grading less (or differently). CBE-Life Sciences Education, 13, 159-166.

Smith, M., Chen, Y., Berndtson, R., Burson, K. M., \& Griffin, W. (2017). “Office hours are kind of weird": Reclaiming a resource to foster student-faculty interaction. InSight : A Journal of Scholarly Teaching, 1, 14-29. https://insightjournal.net/current-and-pastissues/volume-12/

Stommel, J. (2020, March 3). What if we didn't grade? A bibliography. https://www.jessestommel.com/ungrading-a-bibliography/

Struyven, K., Dochy, F., \& Janssens, S. (2005). Students' perceptions about evaluation and assessment in higher education: A review. Assessment \& Evaluation in Higher Education, 30(4), 325-341. https://doi.org/10.1080/02602930500099102 
Tannock, S. (2017). No grades in higher education now! Revisiting the place of graded assessment in the reimagination of the public university. Studies in Higher Education, 42(8), 1345-1357. https://doi.org/10.1080/03075079.2015.1092131

Tinto, V. (1997). Classroom as communities: Exploring the educational character of student persistence. Journal of Higher Education, 68(6), 599-623. https://doi.org/10.2307/2959965

Quick, R. L. (2013). Exploring faculty perceptions toward working with academically vulnerable college students. College Quarterly, 16(4). http://www.collegequarterly.ca/2013-vol16-num04-fall/quick.html

Villarroel, V., Bloxham, S., Bruna, D., Bruna, C., \& Herrera-Seda, C. (2017). Authentic assessment: Creating a blueprint for course design. Assessment \& Evaluation in Higher Education, 43(5), 840--854. https://doi.org/10.1080/02602938.2017.1412396 